\title{
The REACT study: randomised evaluation of assertive community treatment in north London
}

Helen Killaspy, Paul Bebbington, Robert Blizard, Sonia Johnson, Fiona Nolan, Stephen Pilling, Michael King

\begin{abstract}
Objective To compare outcomes of care from assertive community treatment teams with care by community mental health teams for people with serious mental illnesses. Design Non-blind randomised controlled trial.

Setting Two inner London boroughs.

Participants 251 men and women under the care of adult secondary mental health services with recent high use of inpatient care and difficulties engaging with community services.

Interventions Treatment from assertive community treatment team (127 participants) or continuation of care from community mental health team (124 participants).

Main outcome measures Primary outcome was inpatient bed use 18 months after randomisation. Secondary outcomes included symptoms, social function, client satisfaction, and engagement with services.

Results No significant differences were found in inpatient bed use (median difference 1, 95\% confidence interval - 16 to 38 ) or in clinical or social outcomes for the two treatment groups. Clients who received care from the assertive community treatment team seemed better engaged (adapted homeless engagement acceptance schedule: difference in means 1.1, 1.0 to 1.9), and those who agreed to be interviewed were more satisfied with services (adapted client satisfaction questionnaire: difference in means 7.14, 0.9 to 13.4).

Conclusions Community mental health teams are able to support people with serious mental illnesses as effectively as assertive community treatment teams, but assertive community treatment may be better at engaging clients and may lead to greater satisfaction with services.
\end{abstract}

\section{Introduction}

Since the 1990s the relocation of mental health services from hospital to the community has proceeded at a fast pace in England. Despite well equipped community mental health teams, the needs of a substantial subgroup of patients who are severely ill and difficult to engage with services remain difficult to meet. ${ }^{1}$ Assertive community treatment originated from Stein and Test's model of home based treatment, ${ }^{2}$ an alternative approach to admission to psychiatric hospital that was successfully replicated in Australia ${ }^{3}$ and gradually evolved into two specific models: assertive community treatment ${ }^{4}$ and crisis resolution. Assertive community treatment has gained popularity for service users who have problems engaging with services but for whom psychiatric care is essential. Systematic reviews concluded that when targeted at high users of inpatient services, assertive community treatment reduces the costs of care by decreasing frequency and length of admissions. ${ }^{56}$ Other positive outcomes include increased engagement with services, more stability in accommodation, and improved satisfaction for patients and their carers. ${ }^{5}$

It has been difficult to appraise the efficacy of assertive community treatment in England and other European countries with similar service systems. This was because the models of intensive forms of community care investigated were not based closely on such treatment and did not focus on participants who were difficult to engage. ${ }^{7-11}$ Also, comparison groups in these UK studies were more community based than those in US trials. ${ }^{12}$ The Cochrane review concluded that there was a case for a further randomised trial of assertive community treatment in the United Kingdom. ${ }^{5}$

The equivocal evidence has not prevented the Department of Health encouraging the implementation of assertive community treatment as a tertiary model of care. By 2004, 263 such teams existed in England. ${ }^{13}{ }^{14}$ As two teams were being established within our service, we compared the clinical outcomes and cost effectiveness of assertive community treatment with standard treatment from a community mental health team for clients identified as difficult to engage and who were high users of inpatient care. We hypothesised that assertive community treatment delivered by specialised teams operating with a high degree of fidelity to the model would lead to fewer days of inpatient care than standard case management provided by community mental health teams. The results of the cost effectiveness analysis are the topic of a separate paper.

\section{Methods}

We carried out the trial in the inner London boroughs of Camden and Islington. High levels of deprivation give this area one of the highest estimated levels of psychiatric morbidity in the United Kingdom. ${ }^{15}$

Participants were referred from the 13 local community mental health teams and met the following inclusion criteria: living in independent or low supported accommodation within the two boroughs; under the care of the community mental health team for at least 12 months and identified as having difficulty engaging with standard community care; primary diagnosis of serious mental illness (for example, schizophrenia, schizoaffective disorder, other chronic psychosis, bipolar affective disorder); and recent high use of inpatient care (at least 100 consecutive inpatient days or at least five admissions within the past two years or at least 50 consecutive inpatient days or at least three admissions within the past year). Individuals with concurrent problems from substance misuse or personality disorder were eligible if 
these were secondary diagnoses. We excluded patients with organic brain damage.

A panel of clinicians and researchers met each month to consider referred clients that met all but the inpatient bed day criteria and whose mental health problems placed them at major risk from themselves or others despite input from the community mental health team.

We recruited participants between July 1999 and July 2002. Ethical issues are raised in the research of assertive community treatment as such treatment targets patients whose willingness to engage with services and consent to interventions is limited. A study group consisting only of participants who consented to assertive community treatment would therefore have been highly unrepresentative. The evidence for assertive community treatment in the United Kingdom is meagre, but the treatment's national implementation created the need for a valid trial. The trial's conclusions could then be generalised to the client group that is the focus of such treatment. We obtained approval for randomisation of all eligible participants whether or not they consented to referral to assertive community treatment. Only participants willing to give informed consent were interviewed at baseline and follow-up. For those who could not be interviewed, we obtained ethical approval to use data on inpatient bed use from the local computerised patient record system and for collection of the main staff rated secondary outcomes.

\section{Recruitment and randomisation}

Staff of the community mental health teams were asked to discuss the trial with clients who met eligibility criteria and to explain that they would be randomly allocated either to receive care from the assertive community treatment team or to continue with the community mental health team for 18 months (after which they could be taken on by the assertive community treatment team if still clinically appropriate). HK attempted to contact each participant to gain informed consent for the baseline interview. Randomisation took place after the baseline research assessment to reduce any potential interviewer bias. Participants who could not be interviewed were randomised after they refused interview or after three failed attempts to visit them.

Randomisation was supervised by the trial statistician (RB), who prepared participants' numbers for each community mental health team by permuted block randomisation with a block size of eight, ensuring parity between community mental health teams in proportions randomised to assertive community treatment. Participants were randomly allocated to either treatment on an equal basis. The interviewer contacted an administrator at the trial centre who opened the appropriate numbered envelope giving details of the outcome of randomisation. Participants and referrers were informed of the outcome by letter. The 18 month assessment period was dated from randomisation. All interviews were carried out by $\mathrm{HK}$ or $\mathrm{FN}$, who were independent of clinical care but not blind to treatment allocation as data collection necessitated liaison with care coordinators.

\section{Treatment groups}

Participants received care according to nationally recognised models of assertive community treatment ${ }^{416}$ or community mental health team practice. ${ }^{17}$ Local community mental health teams were well established, with integrated health and social care professionals. Table 1 summarises the models of care. Fidelity to the model for the assertive community treatment team was assessed independently through the pan-London assertive outreach study $^{18}$ using the Dartmouth assertive community treatment scale. ${ }^{19}$ An independent researcher used the same
Table 1 Characteristics of assertive community treatment teams and community mental health teams

\begin{tabular}{|c|c|c|}
\hline Characteristic & $\begin{array}{l}\text { Assertive community treatment } \\
\text { teams }^{16}\end{array}$ & $\begin{array}{c}\text { Community mental health } \\
\text { teams }{ }^{17}\end{array}$ \\
\hline Total team case load & 80 to 100 & 300 to 350 \\
\hline $\begin{array}{l}\text { Maximum individual case } \\
\text { load }\end{array}$ & 12 & 35 \\
\hline Availability & $\begin{array}{l}\text { Extended hours (0800 to } 2000 \\
\text { every day) }\end{array}$ & $\begin{array}{l}\text { Office hours only (0900 to } \\
1700 \text { Mon-Fri) }\end{array}$ \\
\hline $\begin{array}{l}\text { Locations for } \\
\text { appointments }\end{array}$ & $\begin{array}{l}\text { Not office based ("in vivo"): meet } \\
\text { client at home, in cafes, parks, } \\
\text { etc }\end{array}$ & $\begin{array}{l}\text { Office based appointments } \\
\text { and home visits }\end{array}$ \\
\hline Contact with clients & $\begin{array}{l}\text { Assertive engagement: multiple } \\
\text { attempts, flexible and various } \\
\text { approaches (for example, } \\
\text { befriending, offering practical } \\
\text { support, leisure activities) }\end{array}$ & $\begin{array}{l}\text { Offer appointments at office } \\
\text { or make home visits }\end{array}$ \\
\hline Commitment to care & $\begin{array}{l}\text { "No drop-out" policy: continue to } \\
\text { try to engage in long term care }\end{array}$ & $\begin{array}{l}\text { Discharge if unable to make } \\
\text { or maintain contact }\end{array}$ \\
\hline Case work style & $\begin{array}{l}\text { Team approach—all team } \\
\text { members work with all clients }\end{array}$ & $\begin{array}{l}\text { Case management-little } \\
\text { "sharing" of work with clients } \\
\text { between team members }\end{array}$ \\
\hline $\begin{array}{l}\text { Frequency of team } \\
\text { meetings }\end{array}$ & $\begin{array}{l}\text { Frequent (up to daily) to discuss } \\
\text { clients and daily plans }\end{array}$ & Weekly \\
\hline Source of skills & $\begin{array}{l}\text { Team rather than outside } \\
\text { agencies as far as possible }\end{array}$ & $\begin{array}{l}\text { "Brokerage": referral to } \\
\text { outside agencies for advice } \\
\text { (for example, social security } \\
\text { benefits, housing) }\end{array}$ \\
\hline
\end{tabular}

measure to rate the model fidelity of all 13 community mental health teams. Model fidelity and content of care received by each group were investigated using both quantitative and qualitative methods and will be described elsewhere.

\section{Outcome measures}

Diagnosis was confirmed (except for non-consenting participants) by structured examination of case notes and participant interviews using a standardised operational criteria checklist. ${ }^{20}$ The primary outcome was the number of days spent as a mental health inpatient during the 18 month period. Secondary outcomes were chosen on the basis of those used in other studies of assertive community treatment ${ }^{5}$ : satisfaction with services, using the client satisfaction questionnaire ${ }^{21}$ modified to include specific questions about assertive community treatment ${ }^{22}$; clinical and social functioning, using the expanded brief psychiatric rating scale, ${ }^{23}{ }^{24}$ health of the nation outcome scales, ${ }^{25}$ and life skills profile $^{26}$; needs assessment, using the abbreviated form of the Camberwell assessment of needs ${ }^{27}$; quality of life, using the Manchester short assessment of quality of life ${ }^{28}$; serious incidents concerning deliberate self harm, violence towards others, and contact with police or forensic services; engagement with services from numbers lost to follow-up, and quality of engagement, using the adapted form of the homeless engagement acceptance scale ${ }^{29}$; factors influencing compliance with medication using the rating of medication influences scale in schizophrenia ${ }^{30}$; use of the Mental Health Act; and substance misuse, using the clinician alcohol and drug scale. ${ }^{31}$ The expanded brief psychiatric rating scale, ${ }^{23}{ }^{24}$ Camberwell assessment of needs, ${ }^{27}$ Manchester short assessment of quality of life, ${ }^{28}$ and adapted client satisfaction questionnaire ${ }^{21}{ }^{22}$ were completed from interviews with clients. The health of the nation outcome scales, ${ }^{25}$ life skills profile, ${ }^{26}$ homeless engagement acceptance scale, ${ }^{29}$ rating of medication influences scale, ${ }^{30}$ and clinician alcohol and drug scale ${ }^{31}$ were completed by care coordinators. All other data were collected from case notes.

\section{Statistical analysis}

An audit before the study informed the calculation of sample size. This showed that patients meeting criteria for assertive 
community treatment had spent a mean 176 days (SD 169, median 133) in hospital in the 24 months before the trial began. Results from the Cochrane review $w^{5}$ showed a difference in duration of admission of over one third in favour of assertive community treatment for seven of the 14 randomised controlled trials that reported this outcome. To have $80 \%$ power in our study for detection of a reduction in mean bed days of one third required 125 patients in each treatment group. Analysis was on an intention to treat basis. Owing to non-normally distributed data, in the primary analysis we used the Mann-Whitney test to compare the median number of inpatient days over the 18 month study period. We used Hodges-Lehmann estimates to calculate confidence intervals for the median difference. Participants who died or emigrated during the study period were excluded. Observed inpatient days are reported, although a sensitivity analysis was carried out by assigning a pessimistic outcome (scaling up observed inpatient days to 18 months) to all patients who were lost to follow-up. This did not substantially change the results. We compared secondary outcomes using $t$ tests for normally distributed quantitative data, Mann-Whitney's test for non-normally distributed data, and $\chi^{2}$ tests for categorical variables. As analyses adjusted for baseline differences gave similar results we show only unadjusted results.

\section{Results}

Between July 1999 and July 2002 we recruited 251 participants into the trial (fig 1). Twenty clients who met all the criteria except for bed days were referred to the panel, 18 of whom were included in the trial. At baseline, $168(67 \%)$ participants consented to be interviewed: 90 of $127(71 \%)$ assigned to the assertive community treatment team and 78 of $124(63 \%)$ assigned to the community mental health team. Care coordinators were unable to complete baseline assessments for three participants (one assigned assertive community treatment, two assigned community mental health care) who were out of contact with services at recruitment. Ninety one of the 124 (73\%) participants in the assertive treatment group and 75 of the 119 $(63 \%)$ in the mental healthcare group who were available at 18 months agreed to the follow-up interview (response rate $68 \%$ ). Both interviews were agreed by 73 (57\%) participants in the assertive community treatment group and $56(45 \%)$ in the community mental health team group.

\section{Participants and teams}

The groups had similar characteristics at baseline (table 2). The median duration of illness was 10 years. The mean number of previous admissions was eight (half of which were involuntary), and the median duration was more than two months. Substance misuse was equally prevalent among clients assigned to assertive community treatment and to community mental health team care: illicit drugs, 37 (29\%) v 29 (23\%); alcohol, 30 (24\%) v 32 $(26 \%)$.

The pan-London assertive outreach study ${ }^{18}$ rated the model fidelity of one of the assertive community treatment teams in our study as high (mean score 4.1 on Dartmouth assertive community treatment $\left.\operatorname{scale}^{19}\right)$ and the other as "assertive community treatment-like" (mean score 3.4). The mean for all 24 London assertive community treatment teams included in the pan-London study was 3.4 (range 2.3 to 4.1 ) and the mean for community mental health teams was 2.7 (range 1.9 to 3.2 ). The 13 community mental health teams in our study had a mean score of 2.7 on the Dartmouth scale. The mean number of face to face contacts during the second nine months of the study was three times greater for participants in the assertive community treatment group than for those in the community mental health team group (49 (SD 49) v 16 (SD 23), difference in means 33, $95 \%$ confidence interval 22.6 to $42.1 ; \mathrm{P}<0.001)$.

\section{Primary outcome}

No statistically significant differences were found between the trial arms in inpatient bed days over the 18 months of follow-up (median difference $1,-16$ to 38 ) or in any other indicator of inpatient service use (fig 2 and table 3 ).

\section{Secondary outcomes}

All ratings of satisfaction were higher for clients assigned to assertive community treatment, and total satisfaction scores were significantly greater (effect size $0.35 \mathrm{SD}$ ). No statistically significant differences were found in clinical or social functioning between groups (table 4). Ratings on the adapted homeless engagement acceptance scale indicated greater quality of engagement with services for clients assigned assertive treatment (effect size $0.29 \mathrm{SD}$ ); fewer clients in the assertive community treatment group were lost to follow-up (defined as out of contact for over three months) than those in the community mental health team group. Serious incidents were equally distributed between the groups. Three clients assigned to

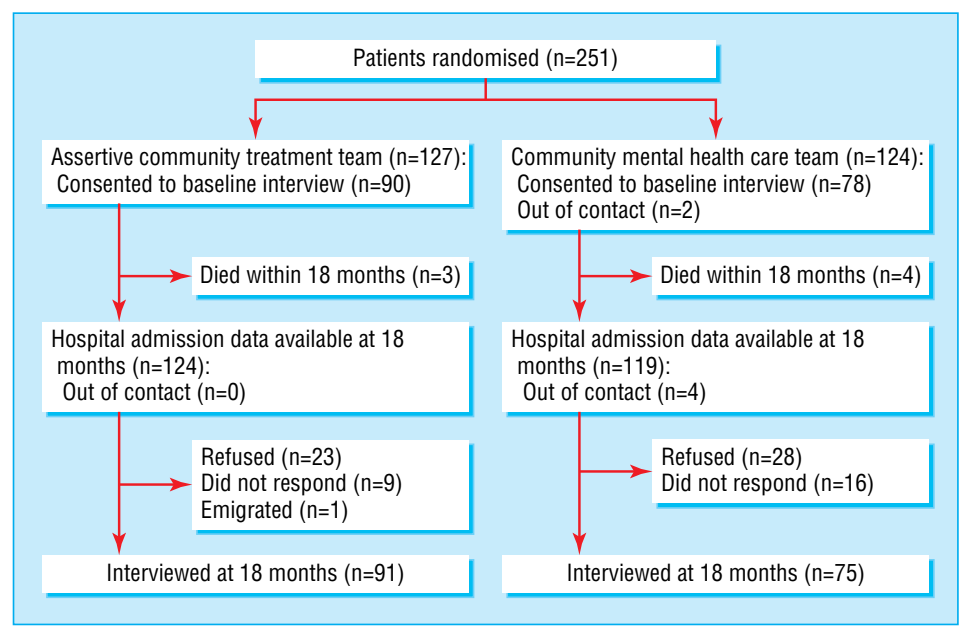

Fig 1 Flow of participants through trial 
Table 2 Baseline characteristics of clients with serious mental illness assigned to assertive community treatment or to community mental health team care. Values are numbers (percentages) of clients unless stated otherwise

\begin{tabular}{|c|c|c|}
\hline Characteristics & $\begin{array}{l}\text { Assertive community } \\
\text { treatment team }(\mathrm{n}=127)\end{array}$ & $\begin{array}{l}\text { Community mental } \\
\text { health team }(n=124)\end{array}$ \\
\hline \multicolumn{3}{|l|}{ Response to interview: } \\
\hline Consented & $90(71)$ & $78(63)$ \\
\hline Refused & $24(19)$ & $27(22)$ \\
\hline No response & $13(10)$ & $19(15)$ \\
\hline Male & $79(62)$ & $68(55)$ \\
\hline Mean (SD) age (years) & $38(11)$ & $40(11)$ \\
\hline Inpatient at recruitment & $60(47)$ & $55(44)$ \\
\hline Recruited through panel & $8(6)$ & $10(8)$ \\
\hline Unemployed $^{*}$ & $81(90)$ & $68(87)$ \\
\hline \multicolumn{3}{|l|}{ Ethnic group: } \\
\hline White & $65(51)$ & $71(57)$ \\
\hline African Caribbean & $52(41)$ & $39(31)$ \\
\hline Other & $10(8)$ & $14(11)$ \\
\hline \multicolumn{3}{|l|}{ Diagnosist: } \\
\hline Schizophrenia & $70(68)$ & $63(65)$ \\
\hline Schizoaffective & $18(17)$ & $15(15)$ \\
\hline Bipolar affective & $6(6)$ & $4(4)$ \\
\hline Delusional disorder & $3(3)$ & $5(5)$ \\
\hline Major depression & $0(0)$ & $2(2)$ \\
\hline Other & $6(6)$ & $8(8)$ \\
\hline \multicolumn{3}{|l|}{ Inpatient service use } \\
\hline \multicolumn{3}{|l|}{ Length of illness (months): } \\
\hline Mean (SD) & $138(102)$ & $160(120)$ \\
\hline Median (interquartile range) & $115(67-181)$ & $130(60-237)$ \\
\hline \multicolumn{3}{|l|}{ No of total admissions: } \\
\hline Mean (SD) & $8(6)$ & $8(5)$ \\
\hline Median (interquartile range) & $7(4-11)$ & $6(4-11)$ \\
\hline \multicolumn{3}{|l|}{ No of admissions in past two years: } \\
\hline Mean (SD) & $2(2)$ & $2(1)$ \\
\hline Median (interquartile range) & $2(1-3)$ & $2(1-3)$ \\
\hline \multicolumn{3}{|l|}{ No of involuntary admissions $\dagger$} \\
\hline Mean (SD) & $4(3)$ & $4(3)$ \\
\hline Median (interquartile range) & $4(2-6)$ & $3(2-6)$ \\
\hline \multicolumn{3}{|l|}{$\begin{array}{l}\text { No of involuntary admissions in past } \\
\text { two years } \dagger\end{array}$} \\
\hline Mean (SD) & $2(1)$ & $2(1)$ \\
\hline Median (interquartile range) & $1(1-2)$ & $2(1-2)$ \\
\hline \multicolumn{3}{|l|}{ No of inpatient days per admission } \\
\hline Mean (SD) & $95(71)$ & $92(63)$ \\
\hline Median (interquartile range) & $69(47-120)$ & $76(51-113)$ \\
\hline \multicolumn{3}{|l|}{$\begin{array}{l}\text { No of days per admission in past two } \\
\text { years }\end{array}$} \\
\hline Mean (SD) & $116(124)$ & $106(103)$ \\
\hline Median (interquartile range) & 75 (48-133) & $76(48-127)$ \\
\hline \multicolumn{3}{|l|}{ Clinical or social function: } \\
\hline Mean (SD) symptoms (EBPRS) ${ }^{*}$ & $36.4(9.1), \mathrm{n}=90$ & 36.2 (11.7), $\mathrm{n}=78$ \\
\hline Mean (SD) quality of life (MANSA)* & $4.4(0.9), n=82$ & $4.2(73), n=73$ \\
\hline Mean (SD) unmet needs (CANSAS) ${ }^{\star}$ & $4.4(3.1), n=90$ & 5.0 (3.2), n=77 \\
\hline Mean (SD) social function (LSP) & 109.9 (16.3), n=126 & 109.2 (15.9), $n=122$ \\
\hline Mean (SD) total score (HoNOS) & $12.4(6.6), n=126$ & $13.3(7.1), \mathrm{n}=122$ \\
\hline \multicolumn{3}{|c|}{$\begin{array}{l}\text { EBPRS=expanded brief psychiatric rating scale; MANSA=Manchester short assessment of } \\
\text { quality of life; CANSAS=Camberwell assessment of needs short assessment schedule; } \\
\text { LSP=life skills profile; HoNOS=health of the nation outcome scales. } \\
\text { *Consented to participate. } \\
\text { tConsented to participate or non-responder. }\end{array}$} \\
\hline
\end{tabular}

community mental health team care and one client assigned to assertive community treatment committed suicide during the study period.

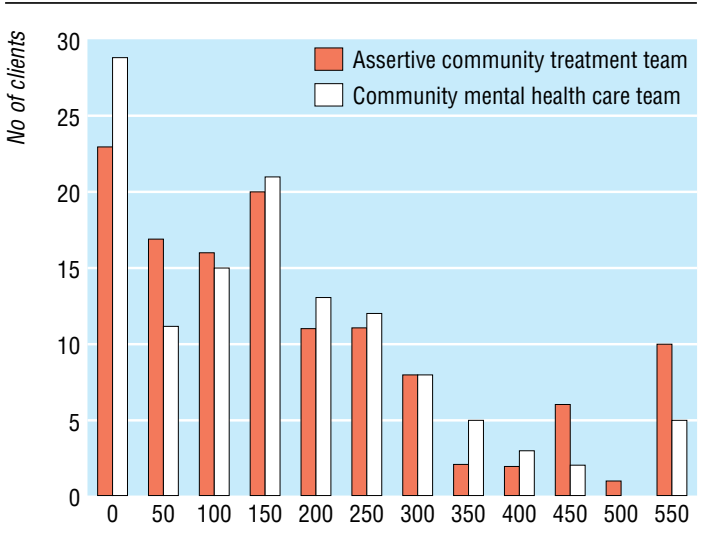

No of inpatient days

Fig 2 Number of bed days spent as an inpatient during 18 months' follow-up of clients with serious mental illness assigned to care by assertive community treatment team or community mental health team

\section{Discussion}

Our study found no evidence of greater clinical efficacy or improvement in social outcomes for recipients of assertive community treatment compared with usual care from community mental health teams.

Our trial tackled the limitations of previous studies ${ }^{7-10}$ by using a randomised controlled design and testing the standard model for assertive community treatment. ${ }^{4}{ }^{16}$ Our assertive community treatment teams had medium to high model fidelity and were representative of such teams in London. ${ }^{18}$ Our referral criteria were strictly adhered to and only a small number of participants not meeting referral criteria for recent inpatient care were recruited through our panel. Primary outcome data were available for all participants. Our findings therefore seem robust for inner city populations in the United Kingdom.

Table 3 Inpatient service use over 18 months for clients with serious mental illness assigned to assertive community treatment or to community mental health team care. Values are numbers (percentages) of clients unless stated otherwise

\begin{tabular}{|c|c|c|}
\hline Variable & $\begin{array}{l}\text { Assertive community } \\
\text { treatment team }(n=124)\end{array}$ & $\begin{array}{l}\text { Community mental } \\
\text { health team }(n=119)\end{array}$ \\
\hline \multicolumn{3}{|l|}{ Total No of inpatient days: } \\
\hline Mean (SD) & $162(161)$ & $144(140)$ \\
\hline Median (interquartile range) & $120(27-231)$ & $130(14-215)$ \\
\hline \multicolumn{3}{|l|}{ No of new admissions: } \\
\hline Mean (SD) & $1.0(1.1)$ & $1.1(1.4)$ \\
\hline Median (interquartile range) & $1(0-2)$ & $1(0-2)$ \\
\hline \multicolumn{3}{|l|}{ No of days per admission: } \\
\hline Mean (SD) & 65 (91) & $52(66)$ \\
\hline Median (interquartile range) & $27(0-95)$ & $27(0-86)$ \\
\hline $\begin{array}{l}\text { No of days to discharge if recruited } \\
\text { as inpatient: }\end{array}$ & $n=60$ & $\mathrm{n}=55$ \\
\hline Mean (SD) & $158(177)$ & 141 (159) \\
\hline Median (interquartile range) & 70 (29-272) & $61(14-215)$ \\
\hline Inpatient throughout & $7(6)$ & $3(30)$ \\
\hline \multirow[t]{2}{*}{ Any admission } & $73(59)$ & $65(55)$ \\
\hline & $\mathrm{n}=73$ & $n=65$ \\
\hline 1 admission & $39(32)$ & $31(26)$ \\
\hline 2 admissions & $23(19)$ & $17(14)$ \\
\hline$>2$ admissions & $11(9)$ & $17(14)$ \\
\hline Involuntary admissions & $60(82)$ & $54(83)$ \\
\hline$\geq 1 \mathrm{PICU}$ admissions & $17(23)$ & $16(25)$ \\
\hline$\geq 1 \mathrm{MSU}$ admissions & $4(<1)$ & $1(<1)$ \\
\hline
\end{tabular}

PICU=psychiatric intensive care unit; MSU=medium secure unit. 
Table 4 Secondary outcomes at 18 months for clients with serious mental illness assigned to assertive community treatment or to community mental health team care. Values are numbers (percentages) of clients unless stated otherwise

\begin{tabular}{|c|c|c|c|c|}
\hline Variable & $\begin{array}{c}\text { Assertive } \\
\text { community } \\
\text { treatment team }\end{array}$ & $\begin{array}{c}\text { Community } \\
\text { mental } \\
\text { health team }\end{array}$ & $\begin{array}{l}\text { Mean difference } \\
(95 \% \mathrm{Cl})\end{array}$ & $P$ value \\
\hline & $\mathrm{n}=91$ & $\mathrm{n}=75$ & & \\
\hline $\begin{array}{l}\text { Mean (SD) symptoms } \\
\text { (EBPRS) }\end{array}$ & $32.9(9.0)$ & $33.5(8.6)$ & $-0.6(-3.3$ to 2.1$)$ & 0.66 \\
\hline $\begin{array}{l}\text { Mean (SD) unmet } \\
\text { needs (CANSAS) }\end{array}$ & $3.3(2.7)$ & $3.4(2.9)$ & $-0.1(-1.0$ to 0.7$)$ & 0.76 \\
\hline \multirow[t]{2}{*}{$\begin{array}{l}\text { Mean (SD) satisfaction } \\
\text { (CSQ) }\end{array}$} & $77.2(20.0)$ & $70.0(20.6)$ & 7.14 (0.9 to 13.4) & 0.03 \\
\hline & $\mathrm{n}=91$ & $\mathrm{n}=67$ & & \\
\hline \multirow{2}{*}{$\begin{array}{l}\text { Mean (SD) quality of } \\
\text { life (MANSA) }\end{array}$} & $4.5(1.0)$ & $4.4(0.9)$ & $0.1 \quad(-0.2$ to 0.4$)$ & 0.56 \\
\hline & $n=124$ & $\mathrm{n}=115$ & & \\
\hline $\begin{array}{l}\text { Mean (SD) social } \\
\text { function (LSP) }\end{array}$ & 119 (16.4) & 115 (19.7) & $4.3(-0.3$ to 8.9$)$ & 0.07 \\
\hline $\begin{array}{l}\text { Mean (SD) total score } \\
\text { (HoNOS) }\end{array}$ & $8.6(4.8)$ & $9.0(5.9)$ & $-0.4(-1.8$ to 1.0$)$ & 0.56 \\
\hline $\begin{array}{l}\text { Mean (SD) influences } \\
\text { on medication } \\
\text { (RoMI): compliance }\end{array}$ & $6.7(2.6)$ & $6.1(2.5)$ & 0.6 (-0.6 to 1.2$)$ & 0.07 \\
\hline $\begin{array}{l}\text { Mean (SD) influences } \\
\text { on medication } \\
\text { (RoMI): } \\
\text { non-compliance }\end{array}$ & $10.8(4.3)$ & $11.4(3.8)$ & $-0.7(-1.7$ to 0.4$)$ & 0.20 \\
\hline \multirow[t]{2}{*}{$\begin{array}{l}\text { Mean (SD) engagement } \\
(\mathrm{HEAS})^{\star}\end{array}$} & 9.1 (3.3) & $8.0(3.8)$ & 1.1 (0.1 to 1.9) & 0.03 \\
\hline & $n=124$ & $\mathrm{n}=115$ & & \\
\hline Lost to follow-up & $2(2)$ & $10(8)$ & $5.96 \dagger$ & 0.01 \\
\hline
\end{tabular}

Serious incidents in

past 18 months:

\begin{tabular}{lcccc}
\hline Homeless & $12(10)$ & $16(14)$ & $1.03 \dagger$ & 0.31 \\
\hline Violenceł & $21(17)$ & $14(12)$ & $1.08 \dagger$ & 0.30 \\
\hline $\begin{array}{l}\text { Deliberate self } \\
\text { home§ }\end{array}$ & $10(8)$ & $13(11)$ & $0.72 \dagger$ & 0.40 \\
\hline Arrested & $23(19)$ & $25(22)$ & $0.38 \dagger$ & 0.54 \\
\hline Forensicf & $9(7)$ & $6(5)$ & $0.22 \dagger$ & 0.64 \\
\hline Prison & $3(2)$ & $4(3)$ & $0.24 \dagger$ & 0.63 \\
\hline Substance misuse: & & & & \\
\hline Alcohol & $25(20)$ & $21(18)$ & $0.14 \dagger$ & 0.71 \\
\hline Illicit drugs & $29(23)$ & $25(22)$ & $0.64 \dagger$ & 0.42 \\
\hline
\end{tabular}

${ }^{*}$ Includes participants who disengaged completely and were out of contact with services therefore assertive community treatment $n=124$, community mental health care $n=119$. $+\chi^{2}$ tests.

$\ddagger$ Victim required hospital treatment.

§Includes participants who committed suicide: one assigned to assertive community

treatment (total $n=125$ ) and three assigned to community mental health care (total $n=118$ ).

१Contact with forensic psychiatric services.

One important limitation of the study was its non-blindness, although this might have been expected to lead the assertive community treatment teams to resist more admissions than the community mental health teams. Likewise, interviewer bias might have been expected to increase differences between the groups. That this was not the case supports the validity of our findings. A second limitation was the response rate for follow-up interviews at which secondary outcome data on symptoms, needs, quality of life, and satisfaction were collected. However, use of a combination of participant and staff rated measures reduced both interviewer and non-response bias as data from staff rated measures on clinical and social function, substance misuse, compliance with drugs, and adverse events were available for all participants.

The number of days spent in hospital was similar for both groups and our primary hypothesis was therefore not supported. We analysed multiple secondary outcomes of which two achieved nominal significance. Any adjustment for multiple analyses would reduce the degree of statistical significance. Bearing this in mind, our results suggest that patients receiving assertive community treatment were better engaged in terms of both quantity and quality of contact with staff, and fewer clients were lost to follow-up. In addition, greater satisfaction with services was reported by clients assigned to assertive community treatment who agreed to be interviewed. These findings suggest that the assertive community treatment approach may be more acceptable to this difficult to engage client group than the standard community mental health team model. This was not, however, associated with any improvement in social or clinical function.

In the context of the UK government's national policy of strongly encouraging the implementation of assertive community treatment, ${ }^{13}{ }^{14}$ our results require further examination. Inpatient mental health services in inner cities are already operating with high admission thresholds, most patients being detained under the Mental Health Act $1983 .^{32}$ Interventions that aim to prevent or reduce admissions are therefore unlikely to succeed. It may also be that the approach of community mental health teams, particularly in inner cities, already incorporates features of assertive community treatment such as relatively low case loads, dedicated inpatient beds, similar staffing structures, and home visits. ${ }^{12}$

Another possibility is that because the assertive community treatment teams in our study were new, lack of experience may have reduced their effectiveness. Finally, an 18 month follow-up may not have been long enough to measure positive change: over a longer follow-up, greater engagement and satisfaction might have an effect on other outcomes.

Our findings should encourage policy makers and service planners to consider whether improved engagement and satisfaction for recipients of assertive community treatment justify its implementation. Further investigation is needed as to whether the elements of such treatment that enhance engagement with services could be incorporated effectively into the work of community mental health teams. Certainly this cannot be achieved through a simple reduction in case load..$^{9} 10$ Assertive community treatment is gaining popularity in Europe, but our results suggest that it cannot be assumed to be preferable to well developed generic community mental health teams.

\section{What is already known on this topic}

Assertive community treatment is one of the most widely researched mental health service interventions

International studies have shown positive reductions in length and frequency of admissions

UK studies of other models of intensive community mental health care have found no advantage over usual care yet assertive community treatment has been implemented nationally

\section{What this study adds}

Assertive community treatment had no benefit over usual community mental health team care for inpatient admissions and clinical or social outcomes

Satisfaction and engagement with services may be greater for recipients of assertive community treatment 


\section{Research}

We thank our funders, the patients and staff of Camden and Islington Mental Health and Social Care Trust, and Peter Tyrer for his chairmanship of the trial's steering group.

Contributors: All authors were substantially involved in the conception and original design of the study, the interpretation of data, the revision of the article for important intellectual content, and approval of the final version. HK and RB carried out the data analysis. MK is guarantor.

Funding: Camden and Islington Health Authority, the King's Fund, and the Department of Health.

Competing interests: None declared.

Ethical approval: Camden and Islington Community and Royal Free Hospital local research ethics committees.

1 Melzer D, Hale AS, Malik SJ, Hogman GA, Wood S. Community care for patients with schizophrenia one year after hospital discharge. BMJ 1991;303:1023-6.

2 Stein LI, Test MA. Alternatives to mental hospital treatment. Arch Gen Psychiatry 1980;37:392-7.

3 Hoult JC. Community care of the acutely mentally ill. Br J Psychiatry 1986;149:337-44

4 McGrew JH, Bond GR, Dietzen L, Salyers M. Measuring the fidelity of implementation of a mental health program model. J Consult Clin Psychol 1994;62:670-8.

5 Marshall M, Lockwood A. Assertive community treatment for people with severe menMarshall M, Lockwood A. Assertive community treatment for
tal disorders. Cochrane Database Syst Rev 2000;(2):CD001089.

6 Mueser KT, Bond GR, Drake RE, Resnick S. Models of community care for severe mental illness: a review of research on case management. Schizophr Bull 1998;24:37-74.

7 Holloway F, Carson J. Intensive case management for the severely mentally ill: controlled trial. Br J Psychiatry 1998;172:19-22.

8 Thornicroft G, Wykes T, Holloway F, Johnson S, Szmukler G. From efficacy to effectiveness in community mental health services. PRiSM psychosis study10. Br J Psychiatry 1998;173:423-7.

9 UK 700 Group. Comparison of intensive and standard case management for patients with psychosis. Rationale for a trial. Br J Psychiatry 1999;174:74-6.

10 UK 700 Group. Intensive versus standard case management for severe psychotic illness: a randomised trial. Lancet 1999;353:2185-9.

11 Marshall M, Bond G, Stein L, Shepherd G, McGrew J, Hoult J, et al. PRiSM psychosis study: design limitations, questionable conclusions. Br J Psychiatry 1999;175:501-3.

12 Burns T, Catty J, Watt H, Wright C, Knapp M, Henderson J. International differences in home treatment for mental health problems: results of a systematic review. Br J Psychia try 2002;181:375-82.

13 Department of Health. National service framework for mental health. London: DoH, 1999

14 Department of Health. National service framework for mental health, five years on. London: DoH, 2004.

15 Glover GR, Robin E, Emami J. A needs index for mental health care. Soc Psychiatry 1998;33:89-96.

16 Department of Health. Assertive community treatment teams. Mental health policy implementation guide. London: $\mathrm{DoH}, 2001$

17 Department of Health. Community mental health teams. Mental health policy implemen tation guide. London: DoH, 2002.

18 Wright C, Burns T, James P, Billings J, Johnson S, Muijen M, et al. Assertive community treatment teams in London: models of operation. Pan London assertive community treatment study part I. Br J Psychiatry 2003;183:132-8.
19 Teague GB, Bond GR, Drake RE. Program fidelity in assertive community treatment: development and use of a measure. Am J Orthopsychiatry 1998;68:216-32.

20 McGuffin P, Farmer A, Harvey I. A polydiagnostic application of operational criteria in studies of psychotic illness. Development and reliability of the OPCRIT system. Arch Gen Psychiatry 1991;48:764-70.

21 Larson DL, Attkinson CC, Hargreaves WA, Nguyen TD. Assessment of client/patien satisfaction: development of a general scale. Eval Program Plann 1979;2:197-207.

22 Gerber GJ, Prince PN. Measuring client satisfaction with assertive community treatment. Psychiatr Serv 1999;50:546-50.

23 Ventura MA, Green MF, Shaner A, Liberman RP. Training and quality assurance with the brief psychiatric rating scale. Int J Methods Psychiatr Res 1993;3:221-44.

24 Overall JE, Gorham DR. The brief psychiatric rating scale. Psychopharmacol Bull 1962;11:22-4.

25 Stein GS. Usefulness of the health of nation outcome scales. $\mathrm{Br} J$ Psychiatry 1999;174:375-7.

26 Parker G, Rosen A, Emdur N, Hadzi-Pavlovic D. The life skills profile: psychometric properties of a measure assessing function and disability in schizophrenia. Acta Psychiatr Scand 1991;83:145-52

27 Slade M, Thornicroft G, Loftus L, Phelan M, Wykes T. The Camberwell assessment of need $(C A N)$. London: Royal College of Psychiatrists, Gaskell, 1999.

28 Priebe S, Huxley P, Knight S, Evans S. Application and results of the Manchester short assessment of quality of life (MANSA). Int J Soc Psychiatry 1999;45:7-12.

29 Park MJ, Tyrer P, Elsworth E, Fox J, Ukoumunne OC. The measurement of engagement in the homeless mentally ill: the homeless engagement and acceptance scale (HEAS). Psychol Med 2002;32:855-61.

30 Weiden P, Rapkin B, Mott T, Zygmunt A, Goldman D, Horovitz-Lennon M, et al. Rating of medication influences (ROMI) scale in schizophrenia. Schizophr Bull 1994;20:297310.

31 Drake RE, Mueser KT, McHugo GJ. Clinician rating scales: alcohol use scale (AUS), drug use scale (DUS), and substance abuse treatment scale (SATS). In: Sederer LI, Dickey B, eds. Outcomes assessment in clinical practice. Baltimore: Williams and Wilkins, 1996.

32 Camden and Islington Mental Health and Social Care Trust. Analysis of acute inpatien services in the care trust. London: Camden and Islington Mental Health and Social Care Trust, 2004

(Accepted 2 February 2006)

doi $10.1136 /$ bmj.38773.518322.7C

Department of Mental Health Sciences, University College London, London NW3 2PF; Camden and Islington Mental Health and Social Care Trust

Helen Killaspy senior lecturer

Michael King professor

Paul Bebbington professor

Sonia Johnson senior lecturer

Department of Mental Health Sciences, University College London Robert Blizard statistician

Centre for Outcomes Research and Effectiveness, University College London

Fiona Nolan nursing research fellow

Stephen Pilling director of centre

Correspondence to: H Killaspy h.killaspy@medsch.ucl.ac.uk 